\title{
The Need for Vitamin D Supplementation among Elderly and Musculoskeletal Pain Patients: A Factor to Mitigate the Severity of COVID-19 in Bangladesh
}

\author{
Mohammad Ali ${ }^{1,2,3 *}$ (D)
}

\author{
${ }^{1}$ Uttara Adhunik Medical College and Hospital, BANGLADESH \\ ${ }^{2}$ Bangladesh University of Professionals, BANGLADESH \\ ${ }^{3}$ North South University, BANGLADESH \\ *Corresponding Author: alibup2018@gmail.com
}

Citation: Ali M. The Need for Vitamin D Supplementation among Elderly and Musculoskeletal Pain Patients: A Factor to Mitigate the Severity of COVID-19 in Bangladesh. Journal of Contemporary Studies in Epidemiology and Public Health. 2020;1(1):ep20005. https://doi.org/10.30935/jconseph/8452

\begin{abstract}
25-Hydroxyvitamin D (Vitamin D) is an important vitamin for humans of all ages. Though this vitamin exists in some foods, Sunlight and regular exercise are needed to synthesis this vitamin in our body. In Bangladesh, the prevalence of vitamin D deficiency in elderly people and patients with musculoskeletal pain is very high. Furthermore, the association between vitamin D deficiency and COVID-19 outcome has been proved. However, in this pandemic situation, to prevent the spread of coronavirus-19, peoples are advised to stay at home as much as possible that abstains from exposure to Sun and outdoor exercise. To mitigate this problem elderly people and patients with musculoskeletal pain should take vitamin D supplementary in this pandemic period in Bangladesh.
\end{abstract}

Keywords: Vitamin D, COVID-19, Elderly, Musculoskeletal pain

Received: 20 Jun. $2020 \bullet$ Accepted: 29 Jul. 2020

To the Editor,

25-Hydroxyvitamin D $(25(\mathrm{OH}) \mathrm{D})$, known as vitamin $\mathrm{D}$, is an essential vitamin that maintains homeostasis of calcium and is vital to people of all ages for general health [1]. This vitamin naturally exists in certain foods and dietary supplements and is endogenously produced as sunlight falls on the skin to promote its synthesis. Regular light to moderate exercise is also related to the good production and utilization of this vitamin. The serum concentration of $25(\mathrm{OH}) \mathrm{D}$ in healthy adults is the accepted indicator of vitamin $\mathrm{D}$ status that measure with values below 30nmol / L ( $\mathrm{nmol} / \mathrm{L}=0.4 \mathrm{ng} / \mathrm{mL}$ ) consider to be insufficient [2].

A systematic 2017 review concluded that vitamin D generally protects against acute respiratory tract infections [3]. The linkages between COVID-19 and vitamin D status have been reported by much circumstantial evidence [4]. The infection developed and began spreading in the northern hemisphere at the time of the winter season (end of 2019) when vitamin D levels are at their lowest point. In the northern hemisphere, too, nations have carried much of the burden of cases and mortality. A cross-sectional analysis carried out across Europe found that COVID-19 mortality in different populations was significantly associated with vitamin D status [5]. The same result was also observed in another study when analyzing levels of vitamin D among COVID-19 patients in other regions [6]. Vitamin D, on the other hand, is essential to the health of the musculoskeletal (MSK) too.
The relationship between vitamin D deficiency and chronic MSK pain among adults and the older population is positive [7]. Special care must be taken especially for older people, as they are at high risk of both COVID-19 and deficiency of vitamin D.

It has been found in the USA and Europe that a wide number (20100 percent) of men and women living in the population are deficient in vitamin D [8]. Prior research has found a 100\% prevalence of vitamin $\mathrm{D}$ deficiency among garments worker in Bangladesh [9]. Other empirical studies have shown a similar scenario (53-100\% prevalence of vitamin D deficiency) in Bangladesh [10,11]. However, the relative vitamin D status of populations is one mostly overlooked factor in Bangladesh that could influence the outcome of COVID-19 as people are advised to stay as much as possible at home that abstains from exposure to Sun and perform regular physical exercise.

Great Britain's government health agencies had recommended that people take supplements with vitamin $\mathrm{D}$ during this pandemic through the summer and autumn. During this time of the rapid increase in the number of COVID-19 patients in Bangladesh, to mitigate the seriousness of COVID-19, the government should take appropriate steps to reduce the risk of vitamin D deficiency among patients aged and MSK pain. Electronic or print media campaigns that would encourage community people, especially the elderly, and patients with MSK pain, to take at least 20 minutes of sunbath each day, take food that contains vitamin $\mathrm{D}$, such as fatty fish, orange juice, beef liver, 
cheese, egg yolks, etc. Health care practitioners will encourage their patients to take supplemental vitamin $\mathrm{D}$ if needed. Additionally, 15-30 minutes of light to moderate home-based exercise is also recommended.

\section{REFERENCES}

1. Veldurthy V, Wei R, Oz L, Dhawan P, Jeon YH, Christakos S. Vitamin D, calcium homeostasis and aging. Bone Res., 2016 Dec 18;4(1):16041. (doi: 10.1038/boneres.2016.41).

2. Lips P, Cashman KD, Lamberg-Allardt C, Bischoff-Ferrari HA, Obermayer-Pietsch B, Bianchi ML, et al. Current vitamin D status in European and Middle East countries and strategies to prevent vitamin D deficiency: a position statement of the European Calcified Tissue Society. Eur J Endocrinol., 2019 Apr;180(4):23-54. (doi: 10.1530/EJE-18-0736).

3. Martineau AR, Jolliffe DA, Hooper RL, Greenberg L, Aloia JF, Bergman P, et al. Vitamin D supplementation to prevent acute respiratory tract infections: systematic review and meta-analysis of individual participant data. BMJ, 2017 Feb 15;356:i6583. (doi: 10.1136/bmj.i6583).

4. Grant WB, Lahore H, McDonnell SL, Baggerly CA, French CB, Aliano JL, et al. Evidence that Vitamin D Supplementation Could Reduce Risk of Influenza and COVID-19 Infections and Deaths. Nutrients, 2020 Apr 2;12(4):988. (doi: 10.3390/nu12061620).

5. Laird E, Rhodes J, Kenny RA. Vitamin D and Inflammation: Potential Implications for Severity of Covid-19. Ir Med J., 2020;113(5):81. Available at: http://imj.ie/vitamin-d-andinflammation-potential-implications-for-severity-of-covid-19/
6. Ilie PC, Stefanescu S, Smith L. The role of vitamin D in the prevention of coronavirus disease 2019 infection and mortality. Aging Clin Exp Res., 2020 May 6;32:1195-8. (doi: 10.1007/s40520020-01570-8)

7. Hirani V. Vitamin D status and pain: analysis from the Health Survey for England among English adults aged 65 years and over. $\mathrm{Br} J \quad$ Nutr., 2012 Apr 14;107(7):1080-4. (doi: 10.1017/S0007114511003965).

8. Holick MF, Binkley NC, Bischoff-Ferrari HA, Gordon CM, Hanley DA, Heaney RP, et al. Evaluation, treatment, and prevention of vitamin D deficiency: An endocrine society clinical practice guideline. Journal of Clinical Endocrinology and Metabolism, 2011;96(7):1911-30. (doi: 10.1210/jc.2011-0385).

9. Mahmood S, Rahman M, Biswas SK, Saqueeb SN, Zaman S, Manirujjaman M, et al. Vitamin D and Parathyroid Hormone Status in Female Garment Workers: A Case-Control Study in Bangladesh. Biomed Res Int., 2017:4105375. (doi: 10.1155/2017/4105375).

10. Hossain HT, Islam QT, Khandaker MAK, Ahasan HN. Study of Serum Vitamin D Level in Different Socio-Demographic Population - A Pilot Study. J Med., 2017 Dec 7;19(1):22-9. (doi: 10.3329/jom.v19i1.34836).

11. Zaman S, Hawlader MDH, Biswas A, Hasan M, Jahan M, Ahsan GU. High Prevalence of Vitamin D Deficiency among Bangladeshi Children: An Emerging Public Health Problem. Health (Irvine Calif), 2017;09(12):1680-8. (doi: 10.4236/health.2017.912123). 